\title{
RELATIONAL SUBJECTS AND RELATIONAL GOODS IN THE NEW CIVIL SOCIETY
}

\section{PIERPAOLO DONATI, MARGARET S. ARCHER, THE RELATIONAL SUBJECT}

Joanna Bielecka-Prus

Maria Curie-Skłodowska University

Pierpaolo Donati and Margaret S. Archer's The Relational Subject is an important contribution to the development of contemporary social theory not because of the authors' well-established reputations in the social sciences, nor because it is their first joint publishing venture (they previously edited the publication Pursuing the Common Good: How Solidarity and Subsidiarity Can Work Together (2008)), but because the book synthesizes relational sociology, the theoretical approach developed by Donati (e.g., 2011), with Archer's approach to the theory of the morphogenesis of subjectivity (e.g., 2000, 2007, 2017).

The book is composed of three parts, though only the first and the conclusion (in the third) were written by both authors together. In Part I, the authors polemicize with theories of social relations at both the individual and collective level in order subsequently to display the distinctness of their own theory in this context. The other parts of the book result from a division of labour: Part II, which concerns the morphological emergence of Relational Subjects in the process of socialization and these Subjects' connections with culture and structure, was written by Archer; Part III, on the concept of relational goods and their function in the new model of civil society, was written by Donati. At first glance, such a layout could give rise to suspicions that the proposed model of Relational Subjects is reproducing the same divisions into micro- and macro-structures that previously harmed the development of social theories. It is thus worthwhile to follow 
the authors' presentation closely in order to evaluate the explanatory power of their ideas and the ramifications. In this review I will attempt to reconstruct the main outlines of the authors' proposed conceptualization of the research object of relational sociology. I will also make a number of critical remarks concerning the concept of how reflexivity is shaped in the process of socialization, and on the ethical bases of relational goods.

It should be emphasized that even in their introduction the authors reject attempts to place them in the role of creators of broad theories clarifying the functioning of society en bloc. They see themselves in the modest role of creators of an "explanatory program" (Donati \& Archer 2015: 4), though in one of his earlier publications Donati (2011) declares outright that this programme is a new paradigm in the social sciences. He considers that classical sociological theories are unable to elucidate the processes occurring in postmodern societies. Functionalism and neo-functionalism, which were initially a source of inspiration for him, do not take into consideration the humanistic dimension of social life. His proposed new theoretical orientation makes social relations the centre of interest, as the proper object of sociological analysis. Society is not a receptacle in which relations emerge, take form, and fall apart: it is those relations. They are neither the ideational schemes of individuals nor the material epiphenomenon of hidden structures. Relational sociology's explicit theses, which have developed within the framework of humanist sociology, mark a new path, avoiding both individualism and holism. A new theoretical orientation has to validate itself by two strategies: it must clearly define its premises concerning the ontology of the social world, the subject matter of research, and the resultant epistemology; and it must undertake discussions with existing theoretical orientations in order to set forth its own demarcation lines.

This is the task the authors imposed upon themselves in the first part of the book. Their main theses can be reduced to the following claims: (a) the crisis of late modern society originates in the domination of two seemingly mutually exclusive discourses - individualism and collectivism; (b) these discourses, realized in the practices of governing (centralization and individualization), lead to the atrophy of social relations, and to individuals' feelings of alienation and loneliness; (c) as the main object of sociological research, the study of subjects in social relations and results of their actions (collective subjects, goods) is not only a new manner of describing social phenomena but also an opportunity to break down the social isolation of the individual and to give social relations their proper value in human life. 
The authors are critical of the two dominant ways of conceptualizing the human being in social theory: as homo oeconomicus and homo sociologicus. Both conceptions fall into the trap of reductionism and conflation (see Archer 2000), which promote an anti-humanist model of social life. In consideration of the theory about the reflexivity of the social sciences as a source of the auto-regulation of social life (Giddens 1976; Hałas 2011), it can not be ruled out that these theories are not only models of but also models for social life. Thus it is even more important to rebuild a humanist sociology capable of overcoming the crisis of modernism, postmodernism, and constructivism, and to return to human beings their immanent properties of dignity and agency.

However, not all sociological theories that declare their subject matter to be social relations are humanistic. The authors very clearly distinguish their proposed relational sociology from "relationalism" (Donati \& Archer 2015: 53), pointing out that the latter derives from premises that are radically individualistic, understanding society as a sphere of networked individuals exchanging transactions. These transactions only appear to create social relations; in actuality they are merely channels for the flow of resources or information, in which individuals are either reduced to "nodes," as in network analysis (e.g., Mustafa Emirbayer, Nick Crossley), or are figurations emerging from the relations that constitute them (e.g., Christopher Powell). Reductionism does not concern solely the individual but paradoxically the relations themselves, which are denied reality (e.g., François Dépelteau). In addition, many of these approaches fail to analyse the social and cultural context in which the relations are situated and the mutual ties between them.

Relational sociology derives from different ontological premises, which can be summarized as follows: (a) man, as a spiritual being, develops in authentic social relations; (b) society is a diverse network of relations between individuals and groups. These relations really exist, and their ontological autonomy is proven by the fact that they have separate, emergent properties that can not be reduced to the properties of the individuals who create them, or to determining structures; (c) a necessary condition for the existence of a relation is the reflexivity of individuals capable of analysing and appraising their relations with other people (and the effects) from the perspective of "We" as "Relational Subjects." Relational Subjects create relational goods, although in certain conditions they may produce relational evils. These products have an influence not only on the persons engaged in the relations, but also on the Relational Subjects' immediate and more 
remote environment; (d) Relational Subjects are by nature dynamic, playing a key role in social and cultural morphogenesis. Social relations do not exist in a vacuum but are situated in social and cultural macrostructures, which yet do not have determining force, as they themselves undergo morphogenesis as a result of the activities of the Relational Subjects. Their analysis does not lead solely to micro-sociological research but encompasses all levels of social reality: micro, meso, and macro, and none of these levels is homologous with the others.

In the succeeding chapters of the book, the authors develop these theses and discuss in detail issues connected with the creation and functioning of Relational Subjects in social life. In claiming the ontological separateness of Relational Subjects, they reject both individualism and holism. They also criticize the position of philosophers who postulate the existence of a Plural Subject. Their main censure concerns support for an aggregational individualism and consequently the creation of a Plural Subject on the frail pillars of a similarity of intentionality (Michael E. Bratman) - an idea rescued by John Searl, who introduced the premise of self-confirming convictions of the existence of such similarities ("I believe that you believe that I believe (...)" (Donati \& Archer 2015: 39)), and Raimo Tuomela, who postulated the existence of a normative system binding the Plural Subject into a unanimous entity. The holistic concept proposed by Margaret Gilbert, in which a Plural Subject emerges from a network of mutual obligations based on a social contract, has also proven unsatisfactory. All these theories assume that the existence of a Plural Subject depends on sharing common intentions, uniformity of thought, or the existence of mutual obligations. The authors of The Relational Subject do not agree with these claims and provide examples to prove them false: the tax system does not compel a sense of community, and musicians in an orchestra do not need to have the same aims to form a group. Thus in order to explain the existence of collective entities, it is necessary to find a point of departure in which the relational dimension of social subjects is taken into account, along with their dynamics and the ability of individuals to reflect on those relations and their effects.

The proposed conception of man is a humanist conception; it does not reduce the human being to the product of social or natural forces. Man is not a closed monad equipped with a self, but by his or her nature is a relational being. His or her activities are directed toward three types of orders: the natural, practical, and discursive. In each of these orders different types of relations are realized: object-object, subject-object, and subject-subject. 
As a result, each of these orders produces properties that constitute the essence of humanity: sense of self, praxis, and symbolic communication. The authors of The Relational Subject have made a close analysis of these orders in previous publications (e.g., Archer 2000: 121-193). This time they concentrate on Relational Subjects, which are defined as social entities orienting their activities toward other people and establishing relations with them: "The subject is social in that he or she is relational" (Donati \& Archer 2015: 32). However, these relations cannot be reduced to an aggregate of individuals connected by networks of dependence or a superior structure; they create an entirely separate level of reality impacting both individuals (e.g., defining social identity) and social structures at the micro, meso, or macro level. They are intentionally constructed by people, but their emergent nature means that their effects can not be foreseen at the moment they are initiated. A relation "is not merely the product of perceptions, sentiments and inter-subjective mental states of empathy, but is both a symbolic fact ('a reference to') and a structural fact ('a link between'). As such, it cannot be reduced to the subjects even though it can only 'come alive' through these subjects" (Donati \& Archer 2015: 143). The authors emphasize that rational choice theory, which understands relations as an exchange based on maximizing individual benefits, excludes the possibility of building relations. Martin Buber's concept of relations that are created in the process of a mutual hermeneutic agreement also gives rise to doubts, as there is a large probability that interpreting the desires of an alter ego by intuition or analogy could be fallible. The conditions that must be fulfilled by a Relational Subject in order to exist do not presuppose either rational calculation ("Me-ness"), or extraordinary empathetic ability ("Thee-ness"), or shared mental content (a Plural Subject).

Who is a Relational Subject? This subject exists solely within relations and refers to a "human person apprehended in making these relations and being made by them" (Donati \& Archer: 54). The authors distinguish two types of Relational Subject: individual (personal) and social. In the first case they point to the relational nature of human beings, who develop in relation to the three above-mentioned orders, and they particularly draw attention to the stratifying-relational dimension of the human self, which is in a constant dialogue between "I," "Me," "We," and "You," wherein these aspects of the human being define and redefine themselves in relation to the social context, the relation with Others. In this sense, every human individual is a Relational Subject. A human being is born with potential abilities and possibilities, which are activated and developed in relations 
with the external world (material and social). The development of a human being can be described as a square divided into four fields, each standing for a successive stage of change. "I," "Me," "We," and "You" are not real entities but internal relations within the individual self, which conducts an endless internal conversation. At the start of his or her road of life, a person discovers his or her objective position in the world and becomes aware of social privileges and limitations ("Me"). Individuals, in order to change their social position to a more advantageous one, can form social relations, creating Corporate Agents; they can mobilize and strive to change their social position ("We") in order to realize plans for their future ("You") (see Archer 2010: 222-252). Corporate Agents are Relational Subjects, which enable the organization of collective activities aimed at the morphogenesis of the existing social order in order to satisfy the needs of people connected by relations ("You") and also the needs of the social environment in which this entity functions. However, the actual life aim of a human being is not the improvement of his social position but realization of ultimate concerns, that is, autotelic values, which are constitutive for our personal identity and which determine who we are and who we will become.

Social (Collective) Relational Subjects are a specific type of social arrangement, which has to fulfil a range of conditions in order to exist. Such an entity can be spoken of only when the individuals creating it are conscious of the existence of the relations linking them and the persons who are engaged in this relation consider it to be an important value. The internal relations between the individuals creating it are essential, but so are external relations with the environment, real feelings of community and solidarity ("We-ness"), and the orientation of a person's own activities toward the relation and the relational good it produces, and not toward the individual persons creating the relation. This means that the Relational Subject can not be reduced to specific relations between individual members of the community or their networks (the exception is a dyad, as a two-person Relational Subject), or to communication processes. Social Relational Subjects function at different levels of the social structure. At the micro-social level these are a kind of relation based on face-to-face contacts (e.g., couples, families). At the meso-social level, they are various kinds of organizations in which a multiplicity of direct and indirect interactions occur. In the latter case, the creation of a sense of community in striving for aims is significantly harder. It is possible when people become aware that the task they are setting themselves can be realized solely through joint action and when individuals engage in maintaining the relation. On the macro scale, 
large international organizations are operating; these are dominated by impersonal relationships and thus they rarely form Relational Subjects, or only when they manage to create systemic and social integration. For this to happen, a "network of brokers" (Donati \& Archer: 192) needs to be developed to mediate between the component individual and social subjects to prevent their isolation; at the same time, the network must not make any attempts to dominate or centralize the organization.

Usually the first Relational Subject that human beings encounter on their life path is their family. Socialization, in the sense of an active and selective process of gradually engaging the child in the world, plays an important role in shaping the ability of the individual to create Relational Subjects. The authors do not agree with Georg Herbert Mead and Lev Vygotsky's concept of the development of the self, in which socialization is a linguistic process and the self, with its properties, is exclusively a social creation. Donati and Archer also consider that views on socialization need to be revised given the world's ongoing individualization and social diversification, the lack of normative harmony, the possibility of developing a Generalized Other, and also the appearance of competing groups in regard to the primary groups that were once exclusively responsible for socialization. In the process of socialization, the individual actively builds his or her own hierarchy of engagement in concerns and relations by relational reflexivity to achieve governance over his or her life. This process is composed of several phases: (a) discernment, during which individuals identify the goods that are important to them and divide them from those that are not; (b) deliberation, in which life priorities are selected; and (c) dedication, in which individuals strive to realize those concerns that are most important, continually experimenting and reorganizing the hierarchy of concerns under the influence of their personal experiences. As a result, a person integrates his concerns into a relatively cohesive plan, which becomes his life compass (Donati \& Archer: 127-141). Choices are not made solely in regard to individual needs: people are connected with other people by diverse social relations and these relations could have a significant impact on their decisions, facilitating or hampering their activities - which in turn determines the quality of those relations, their continuation, or disintegration. Thus the creation of a modus vivendi is closely connected with the relational dimension of personal life. The process of initial socialization can be considered finished when a person manages to create a complementary plan of his own concerns, organizing activities and aims. 
Archer considers that in each of these phases a person faces the necessity of making choices between various orders of importance and attempts to reconcile them. This would not be possible without reflexivity. The authors list several types: (a) communicative-realized in conversations with others, in the course of which a given problem is deliberated upon; (b) autonomous - the subject independently weighs a problem and makes a decision; (c) fractured-the subject's considerations do not lead to the undertaking of activities but solely to increased stress and cognitive disorientation; (d) meta-reflexive-the subject critically analyses his previous findings and actions. This reflexivity is connected with relations in the family; communicative reflexivity appears most often when family relations are very close and create many goods. In the remaining types of reflexivity, the child distances itself from its family, independently designating aims for itself. Archer's research shows that meta-reflexivity most often appeared among young people, while communicative reflexivity was the least common, which would seem to indicate that relations in the families studied were not strong (for more on the subject, see Archer 2012).

The authors consider that if numerous goods are produced in family relations, and the members of the group are mutually caring and involved with each other, a child will try to recreate similar relations in its future life. If a family does not create relational goods or does not create many, the child will seek them in other groups. However, the family environment does not determine the child's future, because the child could be influenced by other groups-for instance, the group of its contemporaries - as well as independently seeking temporary affiliations, trying its strength in various social arrangements. The authors also take note of the fact that in contemporary families the type of relations linking parents and children has changed: from strong ties of dependence and intergenerational solidarity into interpersonal relations based on the exchange of mutual services and the intensification of extra-familial relations, which is often connected with large social mobility. Furthermore, postmodernity does not promote the construction of Relational Subjects. Modern communication media, especially the internet, favours the formation of social relations, but they are most often superficial and deprived of reflexivity.

The above-mentioned process of reflexivity, which is shaped during socialization, is a type of thinking in which the individual submits his own behaviour to evaluation and plans further action. However, for the existence of a Collective Relational Subject it is important to develop relational reflexivity. This happens when subjects who are connected by relations 
appraise those relations and their effects, considering in what manner to improve them in order to create more goods in common, achieve set goals, and form a modus vivendi that is advantageous for the continuation of the relation. It is not a question, in this case, of creating one's own life project but of creating common plans of action. We can speak of their existence when the relation becomes a value toward which the individuals involved orient their activities. The reflexivity of Relational Subjects consists in the parties continually monitoring the relation in internal and external conversations, and also in their thinking about their jointly created goods and their methods of achieving those goods. It is important, however, that what is involved is not the development of a strategy for obtaining goals but the guarantee that the relation created as a result of joint action is desirable and attractive for all the people engaged in it. When such an attitude is lacking, the relation begins to create evil, and ultimately to fall apart, as the authors demonstrate using the example of Anna Karenina and Alexei Vronsky. Relational evils are produced when the parties to the relation begin to orient their activities toward their own benefits and aims, and lack of confidence and discouragement appear.

The main task of Social Relational Subjects is to produce relational goods, which cannot be reduced to the creations of individuals engaged in those relations. These common goods can not be parcelled out, and when the relation disintegrates (e.g., in the case of a divorce), the divided goods lose their relational status. The concept of relational goods originates in Adam Smith's theory, although a broader analysis of such goods appeared only in the 1980s in the work of economists such as Carole Uhlaner (1989) and Benedetto Gui (1996). Relational goods were analysed in the context of research into happiness and interhuman relations involved in the production and consumption of material goods; the relational goods were supposed to intensify this sense of happiness and these relations and at the same time to provide a sense of well-being, increasing cooperation and mutual confidence. The concept of relational goods proposed in The Relational Subject criticizes the ancillary function of these goods in regard to economic processes and also the possibility of their exchange for material goods. The creation of relational goods may be based on mutual services, but it is not a matter of obtaining material benefits, as the priority value is the relation and the desire to preserve it by the parties engaged in it. These goods are not material, although they are socially desirable (e.g., confidence, collaboration, participation, solidarity) and can not be created beyond the Relational Subject. They have emergent properties which mo- 
tivate individuals to strengthen the relation through a symbolic exchange and the realization of a common good pro publico bono. They appear during joint action and the parties to the relation are responsible for their creation, development, or dissolution, as well as their effects for the immediate or wider social environment. They are created when people become conscious that access to existing private or public goods is insufficient. Their beneficiaries are both the people creating the Relational Subject and external entities (e.g., local society). They must be available to the general public and can not be appropriated by anyone.

Two types of relational goods can be distinguished: primary, created in informal groups and direct interactions; and secondary (collective), created in communities in which formal and/or indirect relations predominate. They can also- though it happens very rarely-be produced by organizations acting within the framework of the state or market, on the condition that they abandon the principle of competitiveness and de-bureaucratize their governance strategy. It should be emphasized that in each of these cases the goods are neither private nor public; they do not have a specific individual or collective owner, and moreover they can not change owner. Public goods can be transformed into private ones and vice versa (e.g., through privatization or collectivization) but they can not be changed into relational goods. Such goods can be exchanged between various types of Relational Subjects (e.g., the family and non-governmental organizations). Conditions for the existence of relational goods include the non-instrumental motivation of the engaged persons; observance of the principle of mutuality and solidarity - both internal (within the relation) and external (with the social environment); the orientation of the individuals' activities toward the relation; the appearance of relational reflexivity; and an appropriate budget of time for the creation of such goods. Examples of such relational goods are NGOs or schools established and run by parents on the basis of an agreement with the district, which provides certain material means (e.g., the premises).

One of the most important results of the creation of relational goods and at the same time a generator of such goods is sociability, which is defined as "trust and cooperation among people who act in terms of reciprocal symbolic references and connections" (Donati \& Archer 2015: 301). It arises as the result of joint action and increases in the course of activities as added social value, the emergent effect of the mobilization of networks and of reflexivity in regard to the quality of the relation and means of enlarging its parameters, for instance, through mutuality, confidence, cooperation, 
and inclusion. Social relations also create other types of values-exchange value, use value, and the value of dignity. Some of these may be privileged at the cost of others, as is the case, for instance, in trade relations, in which exchange and use value dominate. Added relational value has an interesting property: its growth not only increases opportunities for the generation of relational goods but also stimulates the valorization of other values.

Relational Subjects are established for the creation of relational goods, although they can also generate evil. Relational evils are produced when human rights are broken, the unjust division of profits is generated, or discriminatory behaviours appear, and the signs of such evil are a decline in the members' mutual confidence, with a lack of "We-ness," the depersonalization of interhuman relations, and the commodification of activities. The main enemies of Relational Subjects, though, are the principle of free competition and the excess rivalry associated with it, state authoritarianism, and the bureaucratization of social arrangements - all of which break social solidarity apart.

Relational Subjects atrophy because these entities easily succumb to colonization by the state or market and become organizations acting in accord with bureaucratic or competitive rules, submitting to the pressure of professionalization and allowing the idea of self-help to be driven out by the idea of profit. The result of such processes is that civil society does not function in a manner that is beneficial for citizens. This can be explained as follows: civil society is premised on being a society that creates conditions for the emergence of various Relational Subjects and their production of relational goods as common goods-such production can not be ceded to the state and market. The aim of decentralization is to weaken the prerogatives of the welfare state and to transfer to citizens many of the activities previously undertaken by the state; the citizens will "create multiple and cooperative citizenship by different kinds of actors/agents: public, private, and relational" (Donati \& Archer 2015: 247). Civil society is based on three main principles or pillars: equality, freedom (in the negative sense of "freedom from" and the positive sense of "freedom to"), and social solidarity. The principle of solidarity is connected with the principle of subsidiarity, whose guarantor can be solely Relational Subjects, not the State. Civil society is composed of four subsystems: the market, the state, informal networks, and the collective Relational Subject. In this civil society model, the State is a configured legal system; it can not be the central axis around which social life is organized, though. And thus the State fills solely an auxiliary function. 
Contemporary civil society is wrestling with many problems, and the chief cause of the disadvantageous phenomena is the action of the state and market. The market acts according to principles set forth by the ideology of neoliberalism, whose main principle is free competition, and whose effect is to deepen social inequality. A welfare state acts to equalize the effects of free market activities and to ensure equal opportunity. A model emerges which is internally contradictory: the growth of consumerism drives the profits of entrepreneurs and increases budget revenues, which are expended on activities to repair the damages inflicted by the free market and artificially inflated consumption. In turn, a restriction of consumption leads to a reduction in the state budget and a lack of funds to improve living standards for the poorest strata of society. The welfare state is unable to resolve social problems, and equalizing the distribution of goods by handouts means the weakest individuals become passive beneficiaries of social programmes. The sole exit from the situation at the macro-social level is an expansion of civil liberties and of the Relational Subjects' field of activities (the creation of cooperatives, which are not oriented toward large profits), and at the micro-social level a change in lifestyle and a limiting of consumerism. Money should not be the dominant form of capital, and particularly, it should not be an autotelic aim. Changes in the sphere of morality are also necessary: individualist ethics should be replaced by an ethics of responsibility, the humanization of social relations, and the growth of ecological awareness.

Given the emergent nature of relational goods and the associated question of the predictability of the effects of Relational Subjects' activities, the authors' analysis of the ethical consequences is important. The authors draw attention to the fact that social inequality is growing in the contemporary world, the pauperization of large human communities is proceeding, and human rights violations are common. It is often pointed out that globalization is responsible for these processes. Such an explanation is unsatisfactory, however, as specific individuals and groups are behind these processes. Classical ethics analyses evil in the context of the intentions of social actors. Who, though, is responsible for the side effects of activities - particularly in a situation where we are dealing with a chain of connected activities whose effects occur far in time and space from the initiating actors? In such situations, individuals and groups are freed from moral responsibility and the blame for such a state of affairs is placed on structures and impersonal processes, while repair of the negative effects is left to the state. In the authors' opinion, these negative processes are cre- 
ated in interhuman relations and the persons creating those relations are responsible for the relational evil they have generated and which only they could have prevented. This is possible only when Relational Subjects reflect social networks as the product of relations and their outcome at every stage of their production, to correct the distribution of goods. An ethics of responsibility should respect not only the principles of freedom and equality but also solidarity and subsidiarity. Without them, it will not be possible to build a real civil society on the global scale.

To summarize, the theoretical perspective proposed by relational sociology is not only a theory of the morphogenesis of the social person, of culture and structure (whose foundation is social relations), but also a plan for a new civil society in which the ethic of responsibility and subsidiarity is respected.

In conclusion, a few critical remarks: the main defect of this book is its very high saturation with new ideas and typologies. These create a complicated network of meanings in which it is very easy to lose oneself. The situation is made even worse by the fact that the authors quite frequently refer to their previous works and sometimes discuss the ideas contained in them in a highly abbreviated manner. For a reader with a slight acquaintance with these works the book is difficult to digest. Furthermore, it might be quite hard to reconstruct the philosophical foundations of the authors' proposed sociological theory if the reader is not familiar with the social ontology of the critical realism of-for instance-Roy Bhaskar, who is not mentioned in The Relational Subject, even in the footnotes. Thus even for a person who is following the authors' arguments carefully, many unresolved questions could arise. I am presenting only a few of them here.

In a polemic with philosophers analysing the ontology of a Plural Subject constructed on collective imaginings or individual representations of the minds of other people, the authors postulate the existence of a Relational Subject, whose foundation is the reflexivity of the engaged subjects. However, the authors do not explain whether all engaged persons should undertake such reflection. A situation can be imagined in which certain individuals will have more potential or capital (analytical, linguistic) and therefore their manner of defining the relation could become dominant. The authors do not in general reflect on the subject of authorities or of symbolic power, either on the micro scale or at the level of social macrostructures.

The analysis of individuals as individual relational subjects is fairly general and meant to serve as a model. However, not all persons taking 
part in the formation of Corporate Agents ("We") are capable of morphogenesis and will remain members of the original subjects of action ("Me"). Archer discussed this process in Being Human (2000: 253-283) and Making Our Way Through the World (2007). In The Relational Subject, the question has been treated very briefly and thus it is not clear how the balanced social identity of a person who does not become part of the active and causal "We" would develop. It is possible to imagine the existence of individuals who are not part of such organizations, who remain passive in regard to the structural restrictions, and who must wait until Corporate Agents initiate morphogenesis. But are they capable of taking full advantage of the results of morphogenesis? Or could a "new edition" of privileged social roles once again pass them by? Similar observations could be made about the process of socialization. Even if we agree that in the contemporary world family relations are significantly weaker-which is a fairly large generalization not taking into account intercultural variations - the family function of socialization in this model is only sketchily discussed. Archer overlooks, for instance, the fact that a child could have different relations with its father and with its mother. Are we in this case dealing with a Relational Subject if both relations are satisfactory for the parties and create relational goods? If we agree with the thesis that a family is a group in which the members develop relational reflexivity, what type of family best supports such a development? From a few passing remarks it can be concluded that this would be a family in which numerous relational goods are produced and which develops communicative reflexives and meta-reflexives. What happens when a child is raised in an orphanage or similar facility? Can such an institution function to stimulate the development of relational reflexivity, and if so, how? What fate awaits individuals who did not have positive patterns of relations, were not able to build a cohesive life plan in the process of socialization, and developed fractured reflexivity? Are they capable of creating Relational Subjects in the same degree as persons who experienced positive relations?

Further doubts could be produced by the concept of relational goods, which in the view proposed in The Relational Subject are deprived of strong axiological foundations. It is not known, after all, how "good" is defined, what its ethical bases are, and what it is to serve. Is the priority a social good, or the good of a human being-which in Catholic social thought, for instance, transcends society? The answer is connected with the question of a human being's position in the world. The omission in the book of a clear attempt to conceptualize the essence of a human being slightly weakens the 
humanist perspective of the theory. The authors claim, in truth, that a human being is a "spiritual being and social relations are one of the essential elements defining what is human" (Donati \& Archer 2015: 258), but it is not known what other elements (agency, rationality, liberty?) define human nature and what is its genesis.

The authors' position on the ethical question is also not known. Relational goods can be various for various Relational Subjects, but are all definitions equally legitimate? Relational solidarity and a sense of satisfaction can also be based on the performance of moral evil. It is not clear if the proposed ethic is a relativist ethic - in which the positive and negative values of objects and persons are relative qualities - or an objectivist ethic, in which the absoluteness of good is assumed (Tatarkiewicz 1989: 25-103). In addition, the authors of The Relational Subject have considerably broadened the sphere of the idea of responsibility, which could give rise to many reservations. First, they include persons who have unintentionally contributed to social evil (and are not thus conscious of the consequences of their acts and not "properly qualified") in the set of responsible agents (Ingarden 1987: 77). This leads to a situation in which an individual's decision and the effect are separated from each other, and thus also agency and its moral qualification; consequently, such an ethics in not cohesive with the concept of agency proposed by the authors. Second, such a broadening of the concept of responsibility causes it to lose its sense, because each of us becomes responsible for social evil— present, past, and future equallybecause it is always possible to indicate a certain chain of deeds in which our actions are one of the links. The idea of reflexivity does not save this position because the authors themselves point out that it varies depending on people's biographical trajectories. The question thus arises: Who is responsible for a lack of sufficient reflexivity - the individual person, or also the other individuals who are in relations with that person? Third, an ethics of responsibility can not be built on a relativistic theory of values, as Roman Ingarden observes (1987: 100-101), but the authors are vague on the question of axiology. It can thus be said that their model of an ethics of responsibility is built without solid axiological foundations.

The book clearly omits to place considerations on the relational properties of social life in the broader context of social theory. Reference is almost absent to Catholic social science, which also analyses social existence as a real, relational, and polymorphic existence, and the common good as a universally available relational good constructed in accord with principles of solidarity and subsidiarity located deep in an axiological sphere and 
closely linked with the good of the human being (John XXIII 1961; Pius XI 1931; Tischner 1982). The authors also do not debate the libertarian concept of the state or communitarian concepts of community life. Nor do they refer to the works of the leading representative of humanist sociology, Florian Znaniecki, who understood the human being in a relational manner (Hałas 2010) and devoted many chapters of his work to an analysis of social relations (Znaniecki 1965).

In spite of a certain lack of completeness that might be felt by the reader after finishing this book, the above remarks should not be treated as a list of defects. It is rather a catalogue of the questions that could be departure points for further discussion of the relational dimensions of social life and their consequences for the functioning of civil society. And even if sceptically inclined readers consider that the project proposed by the authors of The Relational Subject is unfinished, and certain ideas a bit too utopian, it should be emphasized that this is one of the few projects in contemporary sociology in which human subjectivity, both in its individual and its collective aspect, is so strongly stressed — and this is reason enough to read the book.

transl. Michelle Granas

Bibliography:

/// Archer M. 2000. Being Human: The Problem of Agency, Cambridge University Press.

/// Archer M.S. 2007. Making Our Way through the World, Cambridge University Press.

/// Archer M.S. 2012. The Reflexive Imperative in Late Modernity, Cambridge University Press.

/// Donati P. 2011. Relational Sociology: A New Paradigm for the Social Science, Routledge.

/// Donati P., Archer M.S. 2015. The Relational Subject, Cambridge University Press.

/// Giddens A. 1976. New Rules of Sociological Method: A Positive Critique of Interpretative Sociologies, Hutchinson. 
/// Gui B. 1996. On 'Relational Goods': Strategic Implications of Investment in Relationships, "International Journal of Social Economics", vol. 23(10/11), pp. 260-278.

/// Hałas E. 2010. Towards the World Culture Society: Florian Znaniecki's Culturalism, Peter Lang.

/// Hałas E. 2011. Refleksyjność jako zasada i problem teorii społecznej, "Zagadnienia Naukoznawstwa”, vol. 188, pp. 191-202.

/// Ingarden R. 1987. Ksiażeczka o człowieku, Wydawnictwo Literackie.

/// John XXIII. 1961. Mater et Magistra, http://w2.vatican.va/content/johnxxiii/en/encyclicals/documents/hf_j-xxiii_enc_15051961_mater.html, accessed 17.09.2017.

/// Pius XI. 1931. Quadragesimo Anno, http://w2.vatican.va/content/pius-xi/ en/encyclicals/documents/hf_p-xi_enc_19310515_quadragesimo-anno. html, accessed 17.09.2017.

/// Tatarkiewicz W. 1989. Dobro i oczywistość, Wydawnictwo Lubelskie.

/// Tischner J. 1982. Myślenie wedtug wartości, Społeczny Instytut Wydawniczy Znak.

/// Uhlaner C.J. 1989. Relational Goods and Participation, "Public Choice", vol. 62(3), pp. 253-285.

/// Znaniecki F. 1965. Social Relations and Social Roles: The Unfinished Systematic Sociology, Chandler Publishing Company.

/// Joanna Bielecka-Prus - assistant professor in the Institute of Sociology at Maria Curie-Skłodowska University in Lublin. Her research interests are the methodology of qualitative research and discourse analysis, modern sociological theories, and social problems of exclusion and migration. She is the author and co-author of more than fifty publications in Polish and English, including Transmisja kultury w rodzinie i szkole. Teoria Basila Bernsteina [Transmission of Culture in Family and School: The Theory of Basil Bernstein].

E-mail: j.bielecka.prus@gmail.com 
